DOI 10.37882/2223-2982.2021.04-2.14

\title{
ТЕХНОЛОГИЯ КОГНИТИВНОГО УЧЕНИЧЕСТВА В ОБРАЗОВАТЕЛЬНОМ ПРОСТРАНСТВЕ АРХИТЕКТУРНО-ХУДОЖЕСТВЕННОГО ВУЗА
}

\section{TECHNOLOGY OF COGNITIVE APPRENTICESHIP IN THE EDUCATIONAL SPACE OF AN ARCHITECTURAL AND ART UNIVERSITY}

\section{A. Kiseleva}

Summary: The article presents the experience of applying the technology of cognitive apprenticeship in the University of Architecture and Art on the example of studying the discipline "Architectural design". The author defines the technology of cognitive apprenticeship and reveals its essence, which is reflected in the construction of an individual educational trajectory of a student through project activities and social interaction, the transition from the strategy of transferring ready - made knowledge to stimulating self-learning, self-initiation, self-organization and self-esteem, which, in turn, contributes to the formation of an individual artistic style among students-future architects.

Keywords: cognitive apprenticeship, pedagogical technology, creative process, self-development, educational strategy, architectural design.

\author{
Киселева Анна Валерьевна \\ Уральский государственный архитектурно- \\ художественный университет (2. Екатеринбург) \\ kav.7311@mail.ru
}

Аннотация: В статье представлен опыт применения технологии когнитивного ученичества в архитектурно-художественном университете на примере изучения дисциплины «Архитектурное проектирование». Автор дает определение технологии когнитивного ученичества и раскрывает ее сущность, которая отражается в построении индивидуальной образовательной траектории студента через проектную деятельность и социальное взаимодействие, переходе от стратегии передачи готовых знаний к стимулированию самообучения, самоинициации, самоорганизации и самооценке, что, в свою очередь способствует формированию индивидуального художественного стиля у студентов - будущих архитекторов.

Ключевые слова: когнитивное ученичество, педагогическая технология, творческий процесс, саморазвитие, образовательная стратегия, архитектурное проектирование.
$\Pi$ роцесс подготовки будущих архитекторов в архитектурно-художественном образовании неизбежно трансформируется, изменяются подходы, разрабатываются инновационные методики. Под воздействием внешних и внутренних факторов - новые тенденции в строительных и архитектурных технологиях, инновации в градостроительном планировании и культурной среде - происходит пересмотр и самой концепции художественного образования.

Актуальность качественной подготовки специалистов в сфере архитектуры обусловлена социальным заказом общества на профессиональное решение проблем перспективного развития и регенерации окружающей среды, модернизации и реставрации исторической застройки, проектирования новых типов сооружений в соответствии с современными политико-экономическими условиями.

Исторически сложившаяся, апробированная, действующая система архитектурно-художественного образования в России является уникальной и полной, но ее дальнейшее развитие должно быть согласовано с современными позициями мирового профессионального образования и мировыми архитектурными конвенциями в движении к формированию целостной системе, стремящейся к открытости, способной адекватно реагировать на меняющиеся условия и внешние обстоятельства. Ее необходимо трансформировать и развивать, расширяя научные и образовательные задачи.

Архитектурно-художественное образование традиционно считается одной из самых сложных отраслей профессионального образования. В его содержании заложены диаметрально противоположные сферы - искусство и инженерия.

Исходя из этого, задача преподавателя архитектурно-художественного университета - «погрузить» студента в среду его профессиональных интересов, создать искусственный контекст творческого процесса и реальной профессиональной ситуации. В основу этого контекста должна быть заложена коммуникация между участниками творческого процесса, которая позволит гармонично взаимодействовать друг с другом в общении и обучении. Результатом такой коммуникации становиться новое знание, составленное из предыдущего творческого опыта и сообразности. Такое знание, необходимо будущим архитекторам для понимания общего смысла образовательного процесса в архитектурно-художественном 


\section{BУ3e [12].}

Во время обучения в ВУЗе студенты - будущие архитекторы находятся в аутентичной среде, где они применяют свои знания к реальным проблемам в контексте будущей профессиональной деятельности. Атмосфера творчества и активное участие в профессиональной практике являются сильными мотиваторами вовлечение студентов в общий учебный процесс. Образование в профессионально-творческой среде также помогает обучающимся понять цели и содержание обучения, чтобы использовать новые знания в будущей профессии [6].

Поскольку успешность профессиональной деятельности архитектора кроме надлежащей профессиональной подготовки требует высокого уровня креативности, основываясь на профессиональном и жизненном опыте, то внедрение в процесс подготовки будущего архитектора технологии когнитивного ученичества позволит повысить результативность, эффективность и качество образовательного процесса в архитектурно-художественном университете.

Технология когнитивного ученичества - это один из примеров направления конструктивизма в педагогике [8]. На современном этапе развития педагогической науки она рассматривается как образовательная модель, основой которой являются концепции когнитивного развития Ж. Пиаже, социального развития Л.С. Выготского и теория прагматизма Д. Дьюи [7]. Подобная технология предусматривает построение индивидуальной образовательной траектории через проектную деятельность и социальное взаимодействие, переход от стратегии передачи готовых знаний к стимулированию самообучения, самоинициации, самоорганизации и самооценке. Технология когнитивного ученичества является прямым следствием когнитивных теорий Д. Брунера (научение, ориентированное на открытие) и Д. Аусубеля (обучение путем рецепции) [1].

Рассматриваемая технология, это еще и один из примеров концептуализации ситуативного контекста, т.е. социальной установки, в которой студенты учатся применять свои знания непосредственно в профессионально-творческой деятельности. В отношении архитектурно-художественного образования «ученичество» подразумевает овладение студентами - будущими архитекторами приемами профессионально-творческой деятельности. «Когнитивное» - характеризуется применением усвоенных приемов при решении комплекса незнакомых проблемных ситуаций, осуществляя анализ своих познавательных действий, предложенных преподавателем, в контексте ученик - эксперт [4].

Концепция познавательного ученичества имеет свои корни в теориях социального обучения, которые пред- усматривают обучение через накопленный опыт, когда обучающиеся, наблюдая друг за другом, моделируют свои конкретные действия для достижения поставленной учебной цели [2].

Этот подход к образованию, разработанный и описанный А. Коллинзом, Д.С. Брауном и С.Е. Ньюман в статье 1989 года «Когнитивное обучение: обучение ремеслу чтения, письма и математики», применяет отношения мастер-ученик в аудиторной работе [10]. При этом три исследователя спроектировали полезную схему для формирования успешных сред обучения, которые объединяют контент, метод, последовательность и социологию. Благодаря слиянию этих четырех категорий студенческого опыта преподаватели могут включить преимущества когнитивного обучения в свои индивидуальные стратегии обучения [10].

Содержание успешной учебной среды выходит за рамки знания предметной области. Термин «знание предметной области» относится к тем конкретным фактам, цифрам и процессам, которые составляют фундаментальную основу предметной области. Эти знания предметной области важны, но они составляют лишь небольшую часть от общей суммы контента, необходимого студентам для достижения успеха.

Наряду со знанием предметной области, обучающимся необходимо изучить стратегии, для применения их в решения проблем в реальном мире. Другими важными стратегиями являются те, которые помогают студенту определить, какой процесс лучше всего подходит для решения конкретной задачи. Учитывая возможное множество применимых стратегий решения, обучающиеся разрабатывают способ выбора, какая конкретная стратегия является наиболее подходящей.

Социология дает возможность использовать экспертные знания, она подразумевает определение четких целей образовательного процесса, интеграцию социального поощрения и повышения уровня профессиональной квалификации, что в большей степени мотивирует и обосновывает обучение. Присутствие нескольких преподавателей в качестве экспертов демонстрирует, что при решении какой-либо профессиональной задачи можно применять различные подходы и способы решения, а соучастие в творческом процессе сокурсников дает возможность студенту увидеть свои слабые стороны и показать - сильные, как итог - корректировка своих умений и навыков.

Социология формирует у студентов - будущих архитекторов убеждение в том, что социальный контекст способствует появлению продуктивных идей, закладывая основу для создания индивидуального художественного стиля. 
Технология когнитивного ученичества делает познавательные процессы для будущих архитекторов, видимыми в смысле отношений мастер-ученик. Здесь стараются использовать преимущество практического обучения для теоретического обучения. Практическое обучение доводит процессы до видимого завершения проекта, которые остаются невидимыми во время теоретического обучения. Студент видит каждый отдельный шаг работы на пути к конечному продукту и осознает его важность для его завершения. Такое понимание значения подэтапов делает их для него логичными и может быть сохранено и воспроизведено в непосредственной работе. Эта видимость последовательностей действий также должна быть перенесена на невидимые этапы мышления, так что значение для будущих архитекторов здесь также очевидна.

Следуя парадигме технологии когнитивного ученичества, важно сказать, что и методы должны отражать инструктирование вышеупомянутого содержания.

Создатели этой теории Д.С. Браун, А. Коллинз и С.Е. Ньюман выделили следующие методы: тренировка с экспертом, ситуативное моделирование, коучинг, исследование и отражение, метод артикуляции знаний, совокупность которых, способствует открытию новых знаний и управлению когнитивными процессами [11]. Методы преподавания, описанные ими в «модели познавательного ученичества», предназначены для содействия обучения в профессиональной подготовке, и, безусловно, они способны улучшить образовательный процесс в целом.

Ситуативное моделирование - предполагает, что в процессе реализации педагогом (эксперт) учебной задачи обучающиеся наблюдают за его действиями, в основе которых традиционные научно-теоретических знания и набор стандартных профессиональных навыков, а затем выстраивают свою стратегию выполнения задания.

Коучинг - заключается в предоставлении поддержки со стороны эксперта, который наблюдает за действующим процессом, вносит корректировки в выбранную студентом стратегию выполнения работы.

Метод артикуляции - позволяет обучающимся озвучить своим коллегам алгоритм своих действий, проговорить план реализации учебной задачи, в ходе его обсуждения получить рекомендации, как со стороны эксперта, так и со стороны других участников процесса.

Метод «отражение» - дает возможность сравнить свою модель реализации учебной задачи с моделями эксперта и своих коллег.

Изучение - подталкивает студентов в режим решения проблем самостоятельно [11].

Представленная технология эффективно применяется в Уральском архитектурно-художественном университете при изучении дисциплины «Архитектурное проектирование», поскольку на всех этапах обучения она является ведущей профессиональной дисциплиной, где студенты овладевают способами комплексного решения архитектурной задачи с учетом современных стилистических тенденций и проектных нормативов.

Архитектурное проектирование - это вид проектной работы, в основу которой положено архитектурное творчество, то есть деятельность, направленная на создание искусственной среды с новым качеством. Оно сочетает творчество, не формализуя проектные операции, и подлежит постоянному контролю со стороны преподавателя. Все особенности архитектурного проектирования должны быть учтены при подготовке будущих архитекторов во время учебы в университете.

Выделяют четыре основных этапа работы над архитектурным проектом: предпроектный анализ, творческий поиск (нахождение продуктивной идеи для воплощения замысла), творческая разработка (рассмотрение всех вариантов архитектурного решения) и реализация (техническое выполнение).

Так, на этапе предпроектного анализа применяется метод ситуативного моделирования. Эксперты (в большей части преподаватели или наставники) заявляют определенные задачи и дают конкретные отзывы об их исполнении, помогают овладеть особенностями проектирования различных объемно-пространственных структур, типологическими нюансами жилых и общественных сооружений. Студенты, представляют концепцию проекта, перенеся ее в реальную профессиональную ситуацию (например, обсуждение на градостроительной комиссии в администрации города) и алгоритм работы, комментируя каждый этап его реализации. Данный метод дает возможность предложить для обсуждения несколько вариантов концептуальных решений, включая футуристические, создает условия для поиска нестандартного решения функциональных и архитектурно-планировочных задач. На этом этапе происходит постепенное формирование индивидуального архитектурного стиля будущего архитектора.

Метод тренировка с экспертом подразумевает обратную связь со студентами. Обратная связь, как важный элемент в обучении - это процедура получения информации о положение самого образовательного процесса и его участников. Посредством обратной связи преподаватель уведомляет студента не столько о результатах его деятельности, сколько о собственном его восприятии. Это влияет на самооценку студента, отношение к 
преподавателю и ВУзу в целом, мотивацию к получению знаний [3].

Разрабатывая концепцию будущего проекта, обучающиеся сталкиваются со следующей проблемой: у них не выработан навык комплексного применения полученных знаний в рамках изучаемой дисциплины. Это возникает вследствие того, что при проектировании решается системная задача с набором разнородных аспектов (экологические требования, нормативно-правовая база, историко-культурный контекст и др.). Именно поэтому так важна тренировка с экспертом, чтобы научиться вычленять важные моменты и избежать ошибки на начальной стадии проектирования.

Memoд поддержки предполагает, что в некоторых случаях наставник может помочь студенту, предложив различные способы, в решении сложных задач, которые он не может решить самостоятельно. Так, например, на этапе творческого поиска активно предлагается выполнить рабочее макетирование, два-три варианта рабочего макета, в пластилине, картоне и др., для окончательного принятия концепции архитектурного замысла и построения композиции. В процессе этой работы у студента развивается пространственное мышление, формируются понятие «концепция архитектурного замысла», принципы построения целостной композиции и взаимосвязи ее структурных частей. Эти макеты подлежат тщательному анализу и оценке преподавателем, где указываются слабые и сильные стороны проекта, и постепенно вырабатывается концепция архитектурного решения.

Метод артикулячии позволяет студенту проговаривать вслух свои действия, демонстрируя при этом процесс мышления, используя терминологический аппарат изучаемой дисциплины. Если обучающийся испытывает затруднения, то эксперт с помощью наводящих вопросов помогает выстроить ему речевую модель, которая отражает научно-техническую концепцию проекта. Данный метод формирует навык передачи знаний в совместной работе при решении конкретной при решении конкретной профессиональной задачи.

Применяя метод отражения, эксперт дает возможность обучающимся сравнить свою концепцию проекта с концепциями других участников процесса. Определить сильные и слабые стороны, отметить интересные творческие находки [9, с.7].

Например, градостроительная концепция проекта кардинально отличается от объемного проектирования, требуя тщательной проработки ландшафтной организации прилегающего участка. Студентам с недостаточным профессиональным опытом трудно сразу определить особенности этого аспекта. Предлагая концепцию своего проекта, опираясь на концептуальные предложения эксперта, обучающийся тем самым приближается к модели реализации проекта, заданной преподавателем. Цель данного метода - опираясь на свои знания, приблизиться к модели поведения эксперта.

Метод исследования - это площадка для совместных с экспертом научно-технических разработок, где студент берет на себя ответственность в принятии конечного решения. От глубины и полноты исследовательской работы зависит выразительность архитектурно-пространственного решения и обоснованность градостроительной и композиционной концепции, качество проекта, по которому характеризуют степень профессионального мастерства будущего специалиста, а также выносится суждение относительно того, состоялся будущий архитектор как профессионал или нет.

Рассмотренный нами пример применения технологии когнитивного ученичества продемонстрировал на практике свою эффективность при изучении дисциплины «Архитектурное проектирование» в архитектурно-художественном университете, а ее отдельные элементы, преподаватели ВУЗа используют в своей работе повсеместно.

Подводя итог, хотелось бы отметить, еще один важный аспект - технология когнитивного ученичества - это такая кооперация методов, которые активизируют профессионально-творческую деятельность студентов - будущих архитекторов, способствует рефлексии и адекватной самооценке. Это обстоятельство решает еще одну из важных задач архитектурно-художественного образования - формирование индивидуального художественного стиля. Основополагающим в этом вопросе является решение задач и выполнение заданий не по алгоритму, что и проистекает в рамках самостоятельного решения проблемных ситуаций. Творчество начинается непосредственно тогда, когда задача не имеет готового типового решения, или когда общеизвестные способы решения не дают результата [5]. В таком случае знание формируется с помощью предположений, гипотез, интуиции, догадок, а результатом становится открытие нового.

Таким образом, следует констатировать, что в современном архитектурно-художественном ВУзе обучение в аутентичной среде должно включать технологию когнитивного ученичества. Такая технология наиболее ярко отображает взаимосвязь теоретического и практического обучения. Поскольку будущий архитектор должен обладать научным и практическим потенциалом профессиональной культуры, развивать нестандартное мышление, коммуникативные умения и навыки, осуществлять творческий подход к решению не только технологических, профессиональных, но и социально-экономических, экологических, научно-исследовательских проблем. 


\section{ЛИТЕРАТУРА}

1. Авдонина Н.С. Ценности либерального образования / Авдонина // Ценности и смыслы. 2019. №2. С. 63-75.

2. Ванесса П., Деннен К., Горер Дж. Модель познавательного ученичества в учебной практике. Справочник исследований по образовательным коммуникациям и технологиям / П. Ванесса, К. Деннен, Дж. Горер // Научный журнал КубГАУ. 2017. №130 (06). С. 425-439.

3. Байсалбаева М.К. Принципы конструктивной обратной связи в исследовательской практике учителя Международного бакалавриата / М.К. Байсалбаева, Г.С. Сыздыкова // Молодой ученый, 2019. № 6 (244). С. 198-201.

4. Гришина Н.В. Проблема концептуализации контекста в современной психологии / Н.В. Гришина // Социальная психология и общество, 2018. Том 9. № 3. C. $10-20$.

5. Загвязинский В.И. Педагогическое творчество учителя. / В.И. Загвязинский. Москва: Педагогика, 1987. 160 с.

6. Ефимов А.В. Дизайн архитектурной среды - архитектурная профессия / А.В. Ефимов // Асаdemia. Архитектура и строительство, 2019. №3. С. 18-27/

7. Малышев В.С. Конструктивизм и средовой подход: от методологии к методике построения образовательной среды в подготовке кадров высшей квалификации / В.С. Малышев // Известия ВГПУ, №4 (285), 2019. С. 47-51.

8. Плужникова Н.Н. Педагогика конструктивизма как методологическая модель современной культуры / Н. Н. Плужникова // Вестник ассоциации ВУЗов туризма и сервиса, 2016. №3. С. 65-74.

9. Коутон С.У., Харрис А., Джонс Р. Когнитивное ученичество в онлайн-исследовательской лаборатории для аспирантов по психологии / С.У. Коутон, А. Харрис, Р. Джонс // Международный журнал технологий обучения и преподавания в Интернете. 2010. №5 (1). С. 1-15.

10. Collins A., Brown J.S., Newman S.E. Cognitive apprenticeship: Teaching the crafts of reading, writing, and mathematics / Knowing, Learning, and Instruction: Essays in Honor of Robert Glaser / A. Collins, J.S. Brown, S.E. Newman. Hillsdale, NJ: Lawrence Erlbaum, 1989. P. 453-494.

11. Collins A., Brown J.S., Holum A. Cognitive apprenticeship: Making thinking visible / A. Collins, J.S. Brown, A. Holum // American Educator, 15(3), 1991. P. 1-18.

12. Kecskes I. On My Mind: Thoughts about Salience, Context, and Figurative Language from a Second Language Perspective / I. Kecskes // Second Language Research, 2006. Vol. 22. No. 2. P. 1-19.

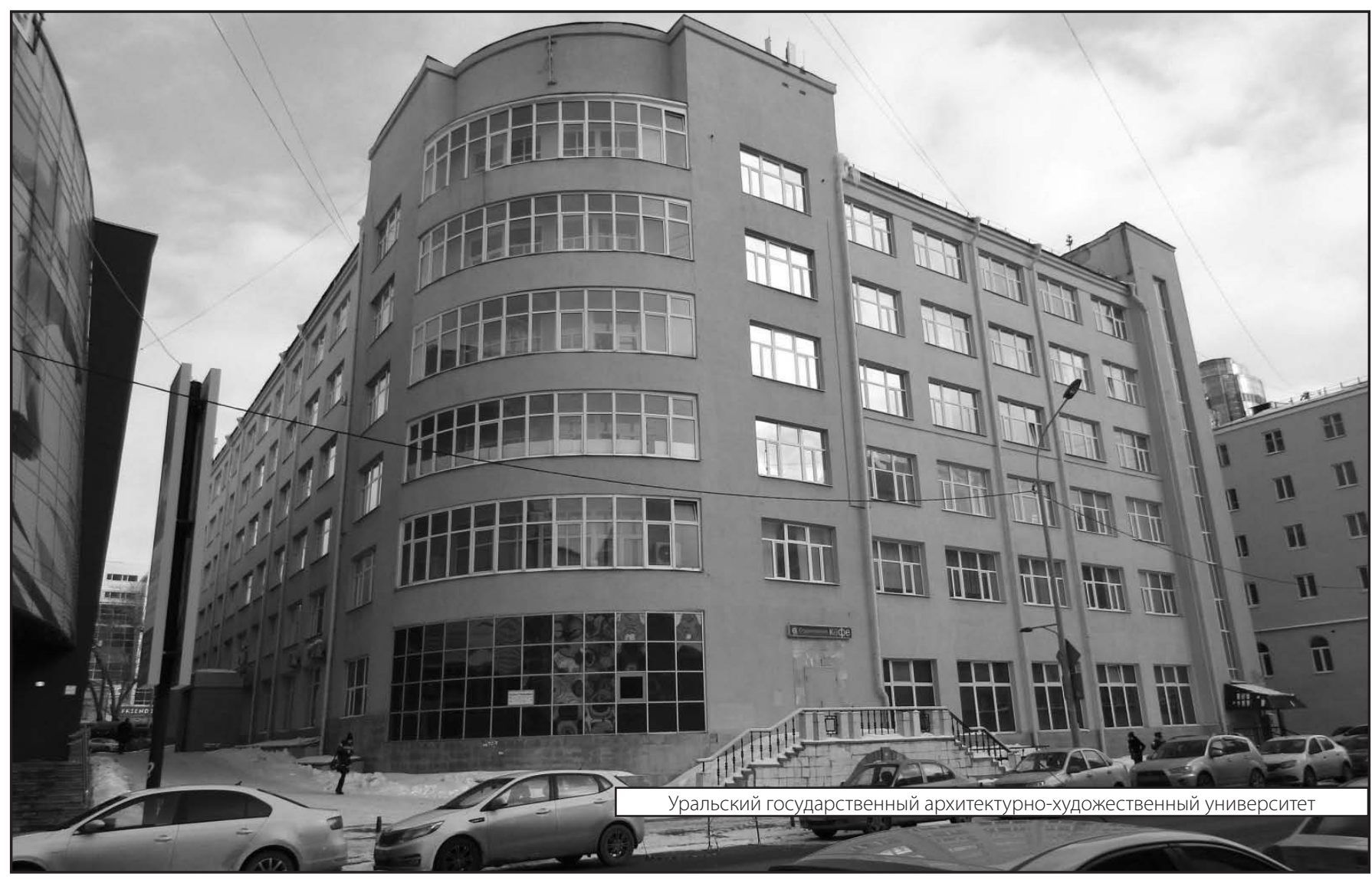

